\title{
The Effect of Basalt Fiber on the Performance of Stone Mastic Asphalt
}

\author{
Altan Cetin ${ }^{1}$, Burak Evirgen ${ }^{2 *}$, Asena Karslioglu $^{2}$, Ahmet Tuncan $^{2}$ \\ ${ }^{1}$ Department of Civil Engineering, Faculty of Engineering, Bartin University, 74110, Bartin, Turkey \\ ${ }^{2}$ Department of Civil Engineering, Faculty of Engineering, Eskisehir Technical University, 26555, Eskisehir, Turkey \\ * Corresponding author, e-mail: burakevirgen@eskisehir.edu.tr
}

Received: 10 April 2019, Accepted: 22 October 2020, Published online: 09 November 2020

\begin{abstract}
Stone Mastic Asphalt (SMA) is a mixture design against rutting caused by intensive and heavy traffic loads. While modified bitumen needs to be used in this mixture, the use of cellulosic fibers is essential to prevent the infiltration of bitumen during the carriage of mixture due to high bitumen content. In this study, the effects of basalt fiber on the performance of SMA mixtures is investigated as an alternative to cellulosic fiber admixtures in the prevention of draindown. Raw materials commonly used in Turkey were chosen as Type-I graded limestone aggregate and B50/70 asphalt cement, according to the General Directorate of Highways. In total, 109 specimens were prepared by a gyratory compactor according to the superpave design method. Sixty of these specimens were basalt fiber added samples with a ratio from $0.1 \%$ to $0.8 \%$ by dry weight aggregate. An addition of basalt fiber of $0.6 \%$ at $25{ }^{\circ} \mathrm{C}$ seriously increases the resilient modulus and tensile strength of the samples. In addition, $0.4 \%$ basalt fiber mixed samples shows that the greatest resistance against permanent deformation according to the results of static uniaxial creep test performed at $40{ }^{\circ} \mathrm{C}$. Basalt fibers have no positive effect when a decrement of bitumen viscosity exceeds the bitumen softening point at the end of repeated uniaxial tests. On the other hand, bitumen draindown and water damage test results are within acceptable limits.
\end{abstract}

\section{Keywords}

stone mastic asphalt, basalt fiber, resilient modulus, bitumen draindown, permanent deformation

\section{Introduction}

Stone Mastic Asphalt (SMA) was first developed in Germany in the 1960s and is used as an asphalt mixture in many other countries. SMA was industrialized to provide high resistance to wear caused by studded tires used in European countries and it has been used over 20 years for this purpose $[1,2]$. The rapid deterioration of asphalt pavements due to increasing traffic loads has led researchers to find new methods and designs for improving the performance of bituminous mixtures. Therefore, SMA is a research area for the improvement of stone mastic asphalt (SMA) and is a working area focused on improving the performance of asphalt pavement mixtures. It has been standardized and widely-used in Turkey, and also applied in many countries around the world, against wear due to heavy traffic conditions, since 1999 [3]. Design performance depends on coarse aggregate content, high filler content, the amount of modified bitumen and the skeleton of aggregate which provides contact surfaces. Therefore, the utilization of SMA on a road surface is expected to increase durability and rutting resistance. In addition, fibers have been used to prevent the infiltration of bitumen while transporting high amounts of bitumen, including gap graded mixtures [4].

The requirement of polymer bitumen modification, high binder content and high temperatures increases this type of asphalt pavement cost in order to achieve expected performance values. While the polymer modification method is used as the most popular bitumen modification technique, it has been reported in the literature that fibers have been used to improve the performance of asphalt mixtures against permanent deformation and fatigue cracking [5].

Moreover, fibers have the potential to improve the cohesive and tensile strength of bituminous mixtures. Therefore, fibers change the viscosity of modified asphalt and increase the dynamic modulus, moisture susceptibility, rutting resistance and freeze-thaw resistance, while reducing the reflective cracking of asphalt mixtures [6]. Miscellaneous fiber types, such as glass, carbon, polyester 
and those of aramid origin, have high strength and stiffness and can be used for the modification of asphalt pavements. Some properties of hot mix asphalts, which are stiffness, resistance against low temperature and plastic deformation behavior, can be enhanced via cellulose fiber and elastomeric chemicals containing special additives [7]. Despite improved performance characteristics, increasing economic and environmental requirements in today's conditions have led researchers to develop new fiber materials. For example, in addition to the extra cost of using cellulosic fiber, there are a number of production difficulties, such as spreading and compaction of mixture during application [8]. Therefore, a relatively new material called basalt fiber with high mechanical performance, low water absorption capacity, stable chemical properties and appropriate temperature ranges, as well as being a nature friendly mineral-based material has been developed. In addition, this product can be directly decomposed in nature without causing any harmful effects. Basalt fiber has a wide range of applications, such as in the construction and automotive industries. It can be alternatively used instead of carbon and glass fiber due to its high physical and mechanical properties to strengthen structural elements

Basalt fiber is an advanced technological industrial product developed by the Russian Research Institute in the Soviet Union after 30 years of research and investigation. The first industrial production furnace was completed in 1985 at a Ukrainian fiber laboratory. Basalt fiber is a typical silicate fiber treated with platinum and rhodium alloy wires, following production with natural basalt rock as a raw material in a furnace after being broken up and melted at $1450-1500{ }^{\circ} \mathrm{C}$ [9]. Recently researchers have been investigating the performance of basalt fiber on asphalt mastic and asphalt pavements as a reinforcing modifier. Liu et al. [10] show that increasing basalt fiber content increases bending resistance and strength up to certain point. Basalt fiber modified asphalt mastic samples have lower creep stiffness and higher creep rate values at $10^{\circ} \mathrm{C}$, although there is improved performance of modified asphalt mastic at low temperatures. Morova [11] investigated the effect of basalt fiber on asphalt mixture with the optimum basalt fiber addition being determined at around $0.5 \%$ according to the strength increment within the results of Marshall stability and volume analysis tests. Wang et al. [12] examined the effect of basalt fiber on bitumen binder and mastic using direct tension and fatigue tests. The resilient modulus was increased by about $26.0 \%$, when the fiber content reached around $4.5 \%$. Furthermore, distributed fibers inside the asphalt matrix released stress concentration and reduced fatigue damage.

Gu et al. [13] report that basalt fiber has an important strengthening effect in the following cases; high asphalt absorption rate, low water absorption capacity, high tensile strength, high modulus of elasticity and high temperature stability. Qin et al. [14] examined the effect of change in basalt fiber lengths and fiber content. Basalt fiber of $6.0 \mathrm{~mm}$ length had much better bitumen adsorption and strength behavior according to the largest interaction area in the matrix. Although crack resistance and high temperature rheological properties of asphalt mastics are influenced by the adsorption and content of the fibers, basalt fiber including asphalt mastic shows the best performance compared with lignin fiber and polyester fiber.

In this study, the effect of basalt fiber on the performance of stone mastic asphalt is investigated. The optimum bitumen content is first determined by the superpave method and the effect of basalt fiber is then investigated using a draindown test, an indirect tensile strength test, moisture susceptibility (water damage test), as well as static and dynamic uniaxial creep tests. The results of the proposed design are compared with a traditional SMA composition consisting of SBS (styrene-butadiene-styrene) modified bitumen and cellulosic fiber. A design optimization is offered for basalt fiber modified asphalt mixtures.

\section{Materials and method}

SMA mixtures contain polymer modified bitumen and cellulosic fiber in standard application. Therefore, a design of reference mixture was made using these raw components to compare the effect of basalt fiber. After this, basalt fiber was added with a range of between $0.1 \%$ and $0.8 \%$ by weight of aggregate for the same mixture design with B50/70 pure bitumen. Common transportation engineering tests were performed to determine the mechanical behavior of the SMA. On the other hand, a draindown test (Schellenberger) was also performed to find whether basalt fiber can be used as an alternative instead of cellulosic fiber.

\subsection{Materials}

Standard raw materials, such as an aggregate, bitumen and filler were used to prepare the SMA mixtures. Certain physical properties of the aggregate determined in the laboratory are given in Table 1. Grain size distribution of the aggregate, including upper and lower limit specifications [3] for SMA Type-I, are given in Fig. 1. 
Table 1 Physical properties of the crushed aggregate used in the SMA mixtures

\begin{tabular}{|c|c|c|c|}
\hline $\begin{array}{l}\text { Size of } \\
\text { aggregate }\end{array}$ & Properties & Related standard & Result \\
\hline \multirow{8}{*}{$\begin{array}{l}\text { Coarse } \\
(19-4.75 \mathrm{~mm})\end{array}$} & $\begin{array}{l}\text { Los Angeles } \\
\text { abrasion }(\%)\end{array}$ & $\begin{array}{c}\text { ASTM C131/ } \\
\text { C131M-14 [15] }\end{array}$ & 24.00 \\
\hline & Soundness (\%) & $\begin{array}{c}\text { ASTM C88/ } \\
\text { C88M-18 [16] }\end{array}$ & 2.90 \\
\hline & Flakiness index (\%) & TS EN 933-3 [17] & 11.00 \\
\hline & Polished stone value & TS EN 1097-8 [18] & 53.10 \\
\hline & $\begin{array}{c}\text { Stripping } \\
\text { Resistance (\%) }\end{array}$ & Tayebali et al. [19] & $45-50$ \\
\hline & Bulk specific gravity & & 2.77 \\
\hline & $\begin{array}{c}\text { Apparent specific } \\
\text { gravity }\end{array}$ & $\begin{array}{c}\text { ASTM C127-15 } \\
{[20]}\end{array}$ & 2.84 \\
\hline & Water absorption (\%) & & 0.86 \\
\hline \multirow{3}{*}{$\begin{array}{l}\text { Fine }(4.75- \\
0.075 \mathrm{~mm})\end{array}$} & Bulk specific gravity & & 2.78 \\
\hline & $\begin{array}{c}\text { Apparent specific } \\
\text { gravity }\end{array}$ & $\begin{array}{c}\text { ASTM C128-15 } \\
{[21]}\end{array}$ & 2.86 \\
\hline & Water absorption (\%) & & 1.02 \\
\hline $\begin{array}{l}\text { Filler } \\
(0.075-0 \mathrm{~mm})\end{array}$ & Specific gravity & TS EN 1097-7 [22] & 2.79 \\
\hline
\end{tabular}

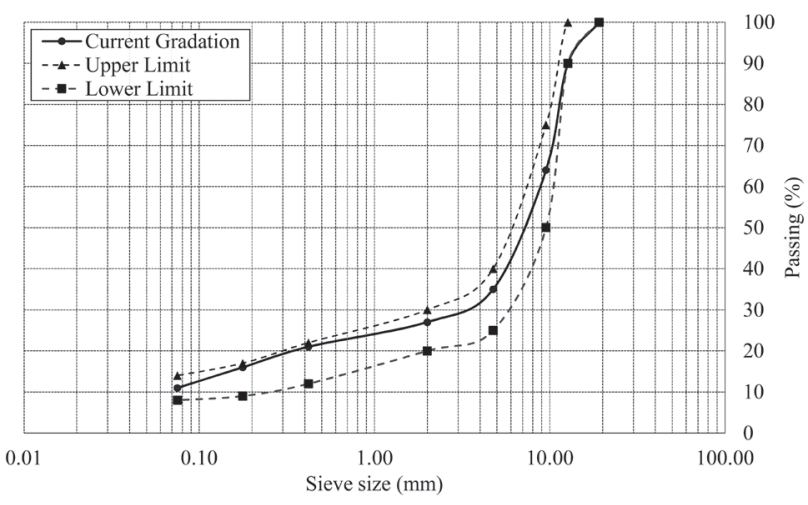

Fig. 1 Gradation curve and specification limits for the SMA Type-I

In the preparation stage of the mixtures, B50/70 bitumen recommended by technical specification [3] was used, as well as polymer modified bitumen providing required criteria was utilized.

The elastomeric type polymer with the commercial trademark Stiren-Butadien-Strien (SBS) was used for bitumen modification. The addition of the SBS polymer prevents permanent deformation, as well as increasing bitumen viscosity and creep resistance at high temperatures. Moreover, it decreases brittleness and, therefore, increases road cracking resistance at low temperatures. This polymer consists of a granular form that contains different combinations made from blocks of polystyrene and polybutadiene of a precise molecular weight. It is added to $4.0 \%$ of bitumen weight and then mixed for 45 minutes using a high shear mixer at a speed of $5000 \mathrm{rpm}$ at $175^{\circ} \mathrm{C}$. The physical properties of the B50/70 bitumen and SBS polymer modified bitumen are given in Table 2 .

In addition, basalt fiber was also used to improve permanent deformation and to prevent the formation of cracks in the road. The length of the basalt fiber was chosen as $12.0 \mathrm{~mm}$ according to the manufacturer. A normal view and microscopic image of the basalt fiber are given in Fig. 2 with the physical and mechanical properties being given in Table 3.

Table 2 Physical characteristics of bituminous binders used in the SMA mixtures

\begin{tabular}{|c|c|c|c|c|}
\hline \multirow[b]{2}{*}{ Properties } & \multirow[b]{2}{*}{ Related standard } & \multicolumn{2}{|c|}{ Result } & \multirow[b]{2}{*}{ Limits } \\
\hline & & B50-70 & $\begin{array}{l}\text { SBS } \\
\text { Mod. }\end{array}$ & \\
\hline $\begin{array}{l}\text { Penetration } \\
\left(25^{\circ} \mathrm{C}, 0.1 \mathrm{~mm}\right)\end{array}$ & & 65.0 & 49.0 & $\begin{array}{l}50-70 \\
50-90\end{array}$ \\
\hline $\begin{array}{l}\text { Retained } \\
\text { penetration }(\%)\end{array}$ & 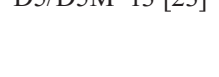 & 72.3 & 76.0 & $\geq 50.0$ \\
\hline $\begin{array}{l}\text { Softening point } \\
\left({ }^{\circ} \mathrm{C}\right)\end{array}$ & D36/D36M-14e1 & 49.0 & 58.0 & $\begin{array}{l}46-54 \\
\text { or }>52\end{array}$ \\
\hline $\begin{array}{l}\text { Increase in } \\
\text { softening point }\left({ }^{\circ} \mathrm{C}\right)\end{array}$ & [24] & 4.0 & 3.0 & $\leq 9.0$ \\
\hline $\begin{array}{l}\text { Ductility at } 5 \mathrm{~cm} / \\
\min (\mathrm{cm})\end{array}$ & D113-17 [25] & $>102.0$ & - & $>100.0$ \\
\hline Flash point $\left({ }^{\circ} \mathrm{C}\right)$ & D92-18 [26] & 304.0 & 318.0 & $>230.0$ \\
\hline Specific gravity & D70-18 [27] & 1.04 & 1.03 & $\begin{array}{c}1.00 \text { to } \\
1.05\end{array}$ \\
\hline Penetration index & C1125-89 [28] & -0.68 & 0.35 & $\begin{array}{l}-1.50 \\
\text { to } 0.70\end{array}$ \\
\hline Loss on heating $(\%)$ & D6/D6M-95 [29] & 0.06 & 0.07 & $\leq 0.50$ \\
\hline
\end{tabular}

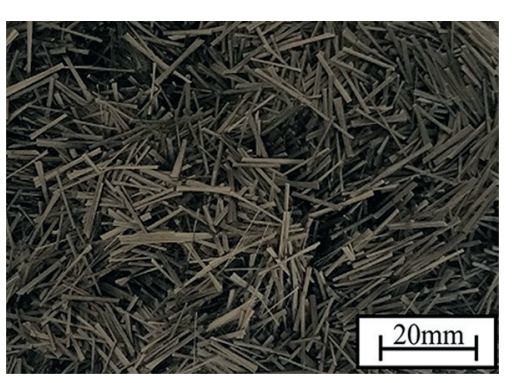

(a)

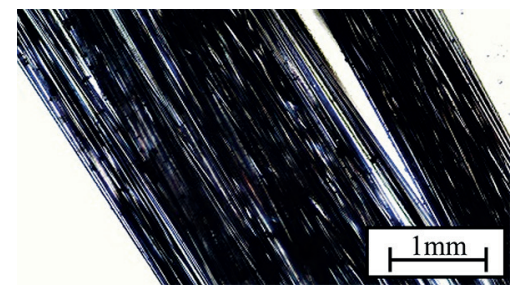

(b)

Fig. 2 Morphology of basalt fiber, (a) Photographic image and (b) Microscopic image (20x magnification factor) 
Table 3 Physical characteristics of bituminous binders used in the SMA mixtures

\begin{tabular}{lc}
\hline Properties & Values \\
\hline Thermal & -260 \\
Operating temperature range $\left({ }^{\circ} \mathrm{C}\right)$ & 982 \\
Melting temperature $\left({ }^{\circ} \mathrm{C}\right)$ & 1450 \\
Thermal conductivity range $\left(\mathrm{W} /\left(\mathrm{m}^{\circ} \mathrm{K}\right)\right)$ & 0.030 \\
& 0.038 \\
Physical/mechanical & \\
Density range $\left(\mathrm{g} / \mathrm{cm}^{3}\right)$ & 2.6 \\
& 2.8 \\
Filament diameter range $(\mu \mathrm{m})$ & 9 \\
Modulus of elasticity $(\mathrm{GPa})$ & 23 \\
Tensile strength $(\mathrm{MPa})$ & 89 \\
Elongation at break $(\%)$ & 4840 \\
Water absorption $(\%)$ & 3.2 \\
\hline
\end{tabular}

\subsection{Mixture design and preparation of specimens}

Samples were prepared according to specifications offered by Technical Specification of Highways [3]. The SMA samples were prepared using a Gyratory compactor (Fig. 3) of $600 \mathrm{kPa}$ pressure, 100 gyrations and $4.0 \%$ air void [8]. $0.6 \%$ cellulosic fiber was embedded into bitumen, and used as a control specimen for bitumen stabilization. $5.0 \%, 5.5 \%, 6.0 \%, 6.5 \%$ and $7.0 \%$ bitumen ratios were used to prepare the SBS modified samples of $100.0 \mathrm{~mm}$ diameter and, in total, twenty-five specimens were tested in this step. The volumetric specific gravity of the compacted samples [30] was specified according to the

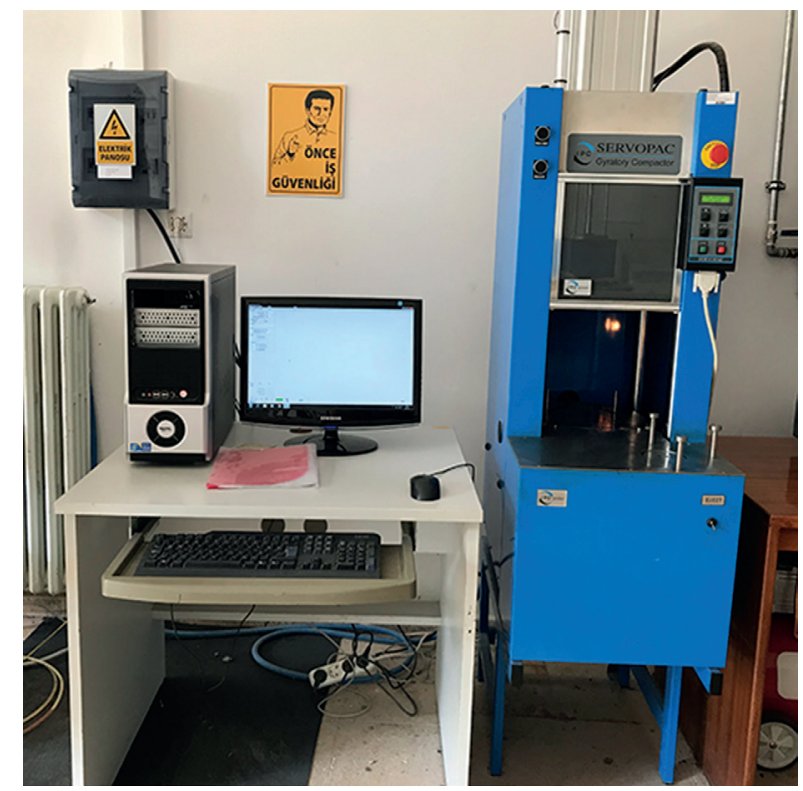

Fig. 3 Gyratory compactor method of theoretical maximum density of loose asphalt samples as mentioned in AASHTO T 209 [31]. Mixture design parameters, such as air void in compacted mixture (VA), voids in mineral aggregate (VMA) and voids filled with asphalt (VFA) are determined according to test results. The design parameters of the controlled and SBS modified mixtures are given in Table 4.

There are generally two methods, wet and dry, for the modification of asphalt mixtures. In the wet method, additives are directly mixed with bitumen. However, additives are adding during the preparation of mixtures in the dry method [32]. In this study, the dry method is used due to the high melting point of basalt fiber. Morova [11] shows that the addition of basalt fiber at an optimum bitumen value gives the same result for each percent of fiber added mixtures. Therefore, samples were prepared at an optimum bitumen ratio $(6.5 \%)$ for basalt fiber included cases. In the preparation of basalt fiber added samples, $1200 \mathrm{~g}$ of aggregate was first mixed with fiber for approximately 2 minutes and then put into an oven at $170^{\circ} \mathrm{C}$ for a minimum of 2 hours. Bitumen was heated up to $145^{\circ} \mathrm{C}$ and then mixed with the aggregate for about 2.0 minutes at an optimum bitumen content. All of the specimens were compacted using a Gyratory compactor under $600 \mathrm{kPa}$ pressure and 100 gyrations. Basalt fiber was added by weight of aggregate at percentages of $0.1 \%, 0.2 \%, 0.4 \%, 0.6 \%$ and $0.8 \%$. It can be seen from Table 5 that void filled with asphalt (VFA) and density decrease while air void in the mixture (VA) and the voids in the mineral aggregate (VMA) increase with an increase in the amount of fiber. This depends on the optimum amount of bitumen and compaction energy. Although

Table 4 SMA mixtures design

\begin{tabular}{lccccc}
\hline Type of mixture & $\begin{array}{c}\text { OAC } \\
(\%)\end{array}$ & $\begin{array}{c}\text { VA } \\
(\%)\end{array}$ & $\begin{array}{c}\text { VMA } \\
(\%)\end{array}$ & $\begin{array}{c}\text { VFA } \\
(\%)\end{array}$ & $\begin{array}{c}\text { Density } \\
\left(\mathrm{g} / \mathrm{cm}^{3}\right)\end{array}$ \\
\hline Control mixture & 6.5 & 4.01 & 16.30 & 75.4 & 2.509 \\
$\begin{array}{l}\text { SBS modified } \\
\text { mixture }\end{array}$ & 6.5 & 4.00 & 16.57 & 75.9 & 2.501 \\
$\begin{array}{l}\text { Specification [3] } \\
\text { S }\end{array}$ & $\geq 5.8$ & $3-4$ & $\geq 16.0$ & - & - \\
\hline
\end{tabular}

Table 5 Volumetric properties of the SMA mixtures with basalt fiber

\begin{tabular}{lccccc}
\hline $\begin{array}{l}\text { Content of basalt } \\
\text { fiber }(\%)\end{array}$ & $\begin{array}{c}\text { OAC } \\
(\%)\end{array}$ & $\begin{array}{c}\text { VA } \\
(\%)\end{array}$ & $\begin{array}{c}\text { VMA } \\
(\%)\end{array}$ & $\begin{array}{c}\text { VFA } \\
(\%)\end{array}$ & $\begin{array}{c}\text { Density } \\
\left(\mathrm{g} / \mathrm{cm}^{3}\right)\end{array}$ \\
\hline $0.1 \%$ & 6.50 & 3.98 & 16.23 & 75.50 & 2.511 \\
$0.2 \%$ & 6.50 & 4.02 & 16.27 & 75.30 & 2.510 \\
$0.4 \%$ & 6.50 & 4.17 & 16.40 & 74.60 & 2.506 \\
$0.6 \%$ & 6.50 & 4.32 & 16.53 & 73.90 & 2.502 \\
$0.8 \%$ & 6.50 & 4.55 & 16.73 & 72.80 & 2.496 \\
\hline
\end{tabular}


the calculated void ratio values for $0.4 \%-0.8 \%$ basalt fiber content are located above the limit value of $4.0 \%$, the maximum increase around $0.5 \%$ did not create serious differences in the results of the performance tests.

\subsection{Test procedure}

First, the amount of infiltrated bitumen was indicated by a binder draindown test for the various ratios of cellulosic fiber and basalt fiber added SMA mixtures. Next, a moisture susceptibility test, and static and dynamic creep tests were also conducted to determine the characteristic behavior of SMA mixtures.

\subsubsection{Draindown test}

Problems related with the infiltration of bitumen may occur during the transportation and laying processes of SMA mixtures that have high bitumen content. Therefore, different methods are used to determine the percent of fiber in the SMA mixtures in order to prevent draindown problems. In this study, a Schellenberger bitumen draindown test [33] was performed as follows. First, aggregate and fiber were stirred at a temperature of $150{ }^{\circ} \mathrm{C}$ for $30 \mathrm{sec}-$ onds under dry conditions. Then the required amount of bitumen satisfying the optimum value was added to the fiber mixed aggregate and the mixture was stirred for no longer than three minutes. Before pouring it into a beaker, the mixture was left to stand for 90 seconds. After pouring the mixture, it was put into an oven at $170^{\circ} \mathrm{C}$ for one hour. After this, the mixture was removed from the oven without shaking and the beaker was weighed again with a sensitivity of $0.1 \mathrm{~g}$, with the weight loss being expressed as a percentage.

\subsubsection{Resilient modulus}

Resilient modulus is widely-used to determine the stressstrain characteristics and elasticity properties of bituminous mixtures. The resilient modulus of asphalt concrete is a basic material parameter used in pavement design and estimation of performance. This parameter was obtained on 21 specimens using an indirect tensile test according to TS EN 12697-26 [34], which is an efficient for practical use in both artificially produced samples and cored specimens. The tests were performed at $25^{\circ} \mathrm{C}$ for a $40 \mathrm{~ms}$ pulse load period with each pulse including rise time and unloading time. Finally, the resilient modulus was determined by applying a $2000 \mathrm{~ms}$ pulse load time with five conditioning pulses followed by a further $3000 \mathrm{~ms}$ pulse load time with five load pulses.

\subsubsection{Static creep test}

Deformation strength caused by permanent traffic loads should be determined for the SMA mixtures to prevent rutting on the asphalt pavement. Therefore, permanent deformation of 21 samples, each of $100 \mathrm{~mm}$ diameter and produced by gyratory compactor, are determined using a static creep test for purpose. This is a practical experiment to determine the permanent deformation and creep rigidity of SMA mixtures. In this test, a ratio of between $5 \%$ and $25 \%$ of compressive load is applied causing deterioration of the specimen. This preliminary stress is a sinusoidal characteristic with a loading time of 0.1 seconds in a period of 1 second and a rest period 0.9 seconds. After this stage, the temporary deformations are measured and the modulus of elasticity is determined. After a pre-loading case, the actual load is applied. The creep test should be carried out at low stress levels (not exceeding $207.0 \mathrm{kPa}$ ) and at low temperatures (not exceeding $40^{\circ} \mathrm{C}$ ) $[8,35]$. This is because the sample will prematurely deteriorate without obtaining real creep data. Finally, the resilient modulus of each sample is calculated at 1, 10, 100, 1000 and 3600 seconds and deformation vs. time curves are drawn. In this step, a minimum of three specimens, including the experimental sets, are carried out with a single loading of $200 \mathrm{kPa}$ at a temperature of $40^{\circ} \mathrm{C}$ for 60 minutes.

\subsubsection{Dynamic creep test}

In the dynamic creep test, stresses in the waveform of haversine with different loading and rest periods are applied. This test is important due to it better reflecting traffic loads. Therefore, a uniaxial pressure of $200 \mathrm{kPa}$, a loading time of 0.1 seconds and a resting time of 0.9 seconds were applied. Experiments were carried out on 21 specimens at $50^{\circ} \mathrm{C}$ up to the 3600 revolutions of loading period or continued up to the limits of the displacement transducers. The value of strain and number of repetitions of yield were determined at the point where the creep curve reaches the third region [36, 37].

\subsubsection{Moisture susceptibility test}

The moisture susceptibility test of the SMA mixtures is defined as the disturbance of the asphalt mixture by water. If water intrudes into the asphalt mixture, it causes damage to the bond between the aggregates and the asphalt binder, thereby accelerating the deterioration on the pavement $[38,39]$. In this step, the moisture susceptibility test was conducted according to the AASHTO T283 [40] procedure as follows. First, each mixture group of optimum 
bitumen content was divided into two groups with each having at least three specimens with close specific gravity values. The indirect tensile strength of 21 conditional and 21 unconditional samples were determined. The conditional samples were saturated by applying a vacuum for about 5 minutes (Fig. 4(a)) and wrapped tightly in a plastic film layer. Then each wrapped sample was placed into a plastic bag containing $10 \mathrm{ml}$ of water. Subsequently, the samples were kept inside a freezing-thawing machine for 16 hours at $-18^{\circ} \mathrm{C}$ (Fig. $4\left(\right.$ b)) and for 24 hours at $60^{\circ} \mathrm{C}$ in a water bath (Fig. 4(c)). Finally, the samples were subjected to an indirect tensile test after waiting 2.0 hours at $25^{\circ} \mathrm{C}$ in a water bath.

\section{Results and discussion}

\subsection{Draindown test}

The bitumen infiltration values of basalt fiber were added to the proposed mix designs at various fiber contents were compared with traditional SMA mixtures containing

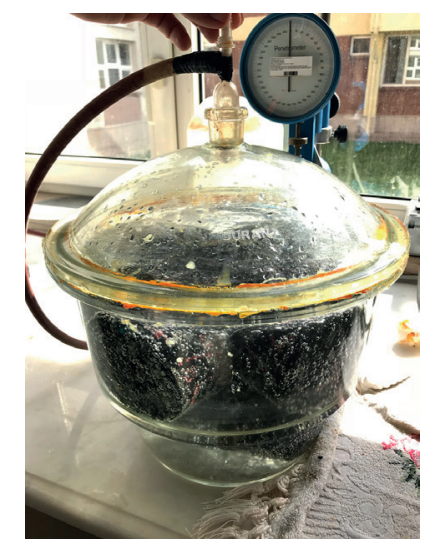

(a)

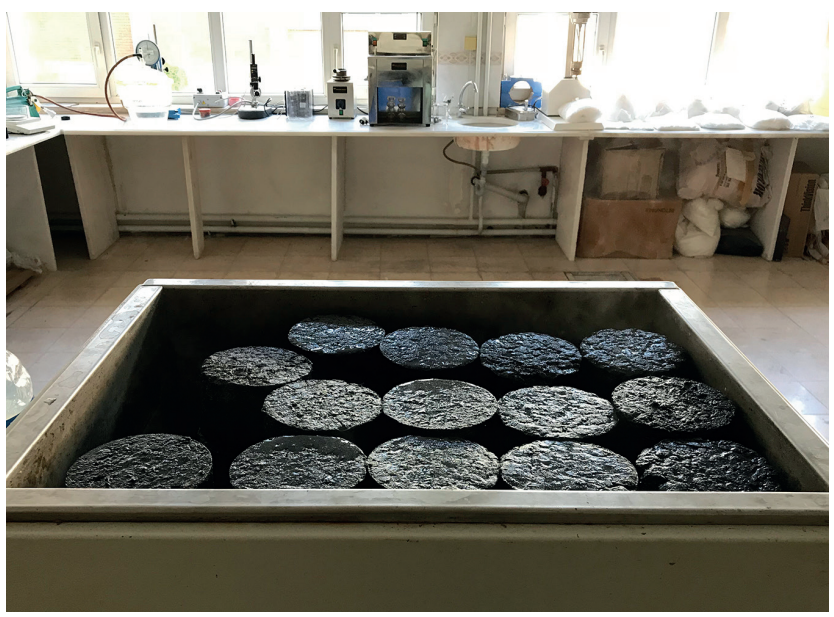

(c)

Fig. 4 The conditioning procedure of the specimens, (a) Vacuum application, (b) Freezing step and (c) Heating in a water bath cellulosic fibers. Both additives were added as $0.1 \%$, $0.2 \%, 0.4 \%, 0.6 \%$ and $0.8 \%$ of the weight of the mixtures. The test results according to the Schellenberger method are given in Fig. 5. The results show that increasing the amount of additive decreases bitumen infiltration. It is evident that basalt fiber provides less stabilization around $2.0-3.0 \%$ of the mixture compared to cellulosic fiber, since the viscosity of the polymer bitumen plays an important role. $0.6 \%$ and $0.8 \%$ basalt fiber and cellulosic fiber added mixtures have about same draindown values individually. Therefore, it is appropriate to select the optimum amount for basalt fiber as $0.6 \%$ by considering other performance test results. On the other hand, all of the specimens exceeded the minimum draindown value of $0.3 \%$ as mentioned as standard according to the results.

\subsection{Resilient modulus}

Resilient modulus is defined as a ratio of applied stress to recoverable displacement. When the additives in a mixture increase, the resilient modulus of the mixtures also tends to increase. After it reaches the maximum value of $0.6 \%$ fiber content, this parameter starts to decrease in value as shown in Fig. 6. The addition of basalt fiber to the SMA mixtures improves rigidity and resistance against deformation. The resilient modulus of the specimens

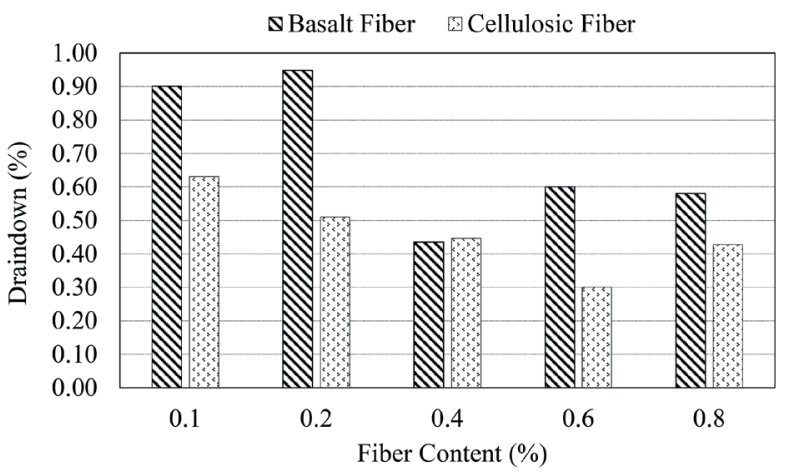

Fig. 5 Draindown test results due to the fiber content

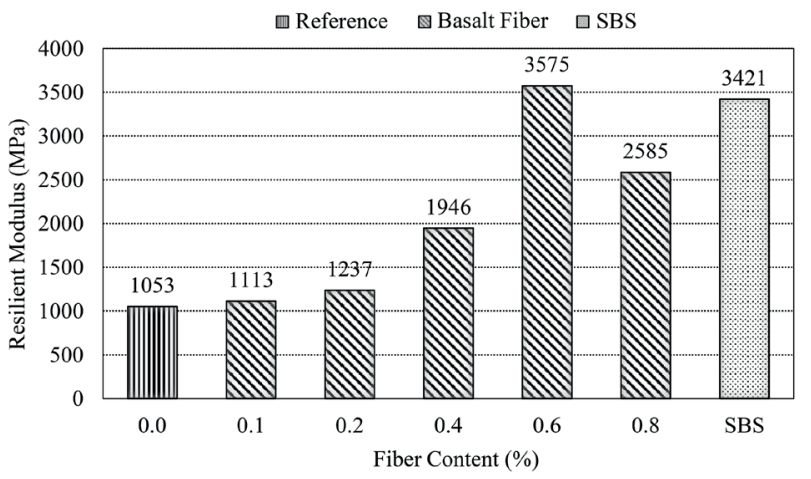

Fig. 6 Change in resilient modulus values due to the fiber content 
prepared at an optimum content of $0.6 \%$ are $240.0 \%$ and $45.0 \%$ greater than the control samples and SBS added mixtures. Moreover, the indirect tensile stress, rigidity and creep behavior of basalt fiber increased remarkably at lower temperatures according to previous studies [10, 12].

\subsection{Static creep test}

The test results of the basalt fiber and SBS added mixtures compared to control samples on the time-displacement curves of mixtures are given in Fig. 7. The axial strain values of all the fiber added specimens decrease compared with the control samples. The best results in terms of resistance against permanent deformation were obtained at $0.4 \%$ basalt fiber added mixtures. It can be seen that the amount of deformation increases in the initial loading period for fiber ratios higher than this value. In addition, sudden deformation behavior is observed in the first stage of the curves due to the void ratio of the mixtures. On the other hand, a deformation value of $0.4 \%$ basalt fiber added specimens is greater than the reference sample and the SBS added specimens, with the ratios of $108.0 \%$ and $36.0 \%$, respectively. These results prove that the addition of basalt fiber improves the deformation properties of the mixtures at high temperatures.

\subsection{Dynamic creep test}

It can be seen from Fig. 8 that basalt fiber added curves are close to each other and close to the control sample curve in an examination of permanent deformation resistance under the dynamic effects arising from traffic load simulation. Bitumen became more viscous and basalt fiber in the matrix lost its effectiveness since the test temperature $\left(50^{\circ} \mathrm{C}\right)$ was greater than the softening point of bitumen. The slopes of the deformation curves of the control sample and mixture that contained $0.1 \%$ basalt fiber remained constant at the second zone. However, the slopes of the other curves for $0.2 \%, 0.4 \%$ and $0.6 \%$ basalt fiber added mixtures increased after 2500 cycles and passed through to the third zone. This situation can be attributed to a reduction in the cohesion of the bitumen because of the increase in the proportion of basalt fiber in the matrix. On the other hand, higher displacement values were achieved under a small number of cycles due to a lack of confining pressure. In addition, the bitumen softening point of the SBS modified samples was not exceeded. Therefore, it has less deformation than both control specimens and the basalt fiber added ones. It should also be noted that excessive displacement behavior was observed in the $0.8 \%$ basalt fiber included specimens (Fig. 9) and that meaningless results were obtained in this case due to its heterogeneous structure. As a result, the permanent deformation curve of the related specimen was removed in Fig. 8.

\subsection{Moisture susceptibility test}

The indirect tensile strength values of the conditioned and unconditioned specimens are given in Fig. 10. It can clearly be seen that maximum value obtained at $0.6 \%$ fiber added mixture was greater than the $75.6 \%$ and the $11.7 \%$ of

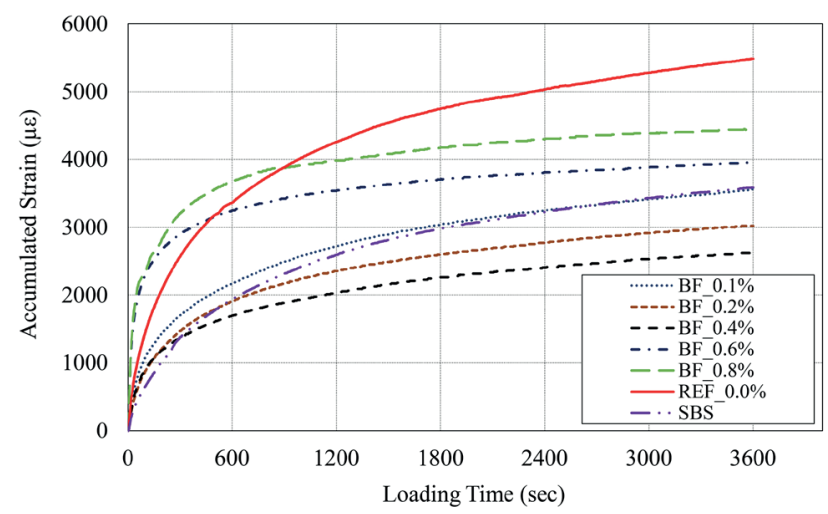

Fig. 7 Time-accumulated strain curves in the static creep test

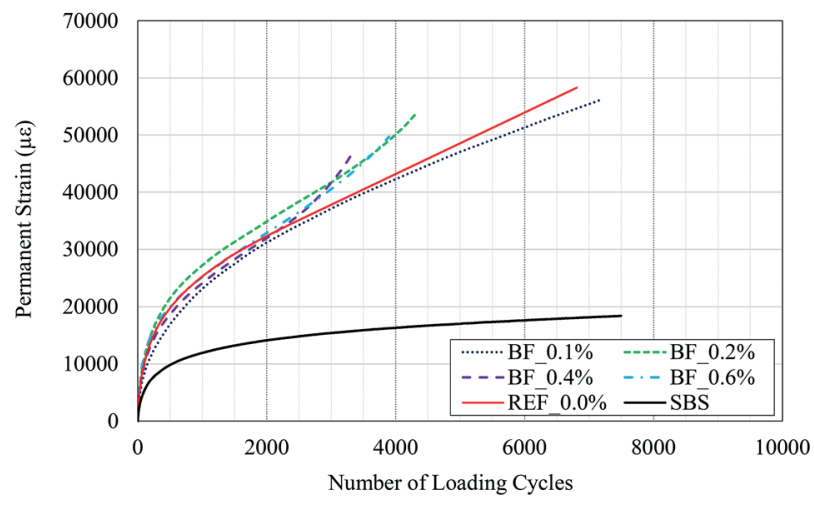

Fig. 8 Loading cycles-permanent deformation curves in the dynamic creep test

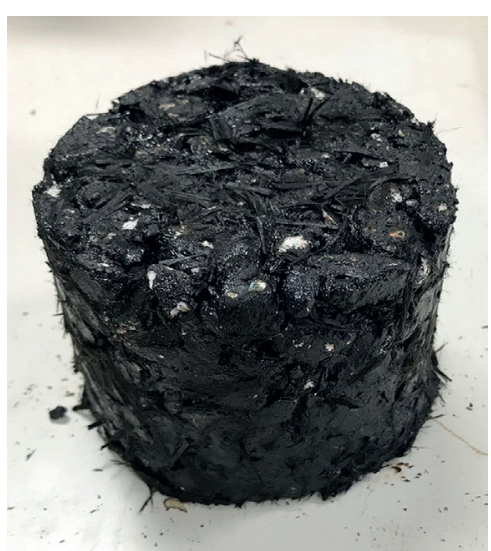

Fig. 9 An excessive heterogeneous matrix due to surplus fiber content 
the control sample and the SBS added samples for conditioned cases, respectively. In addition, $105.0 \%$ and $11.6 \%$ increment values were observed in the same order for the unconditioned cases. Although the tensile strength of the other specimens increased up to the amount of this fiber content, it decreased in the case of the $0.8 \%$ fiber containing samples. The moisture susceptibility results of the basalt fiber addition improved the properties of the asphalt in terms of tensile creep behavior and cracks at low temperature, as well as satisfying the resilient modulus test results. Furthermore, the numerical index of the resistance against the effect of water is expressed as the inverse ratio between the resistance to the original strength and the strength after freeze/thaw conditioning, as given in Fig. 11. This tensile strength ratio (TSR) of $0.1 \%$ and $0.8 \%$ basalt fiber added samples and the control underperformed the value of $70.0 \%$. The maximum TSR obtained at the $0.4 \%$ basalt fiber added sample is greater than the $15.2 \%$ and $4.7 \%$ of the control sample and SBS added samples, respectively. In addition, the $0.6 \%$ basalt fiber specimens have $11.0 \%$ higher strength than the control samples as well as a close result with the SBS added case. Despite the fact that the addition of basalt fiber to the SMA mixtures increases the adhesion between aggregate and bitumen, the water effect decreases adhesion.

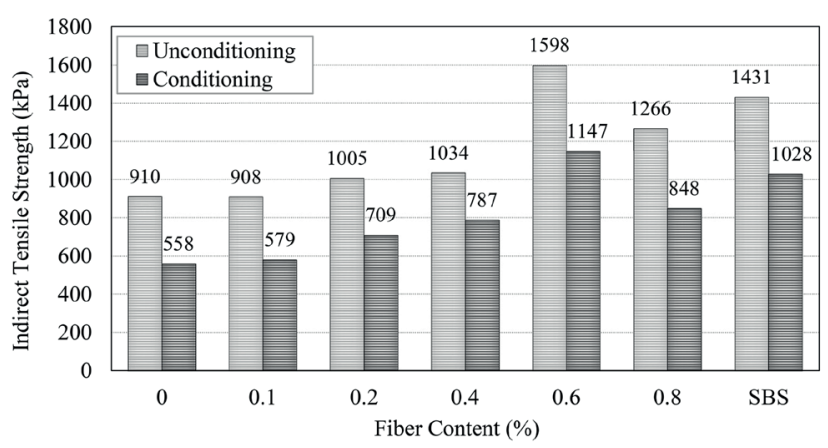

Fig. 10 Indirect tensile strength of unconditioned and conditioned specimens

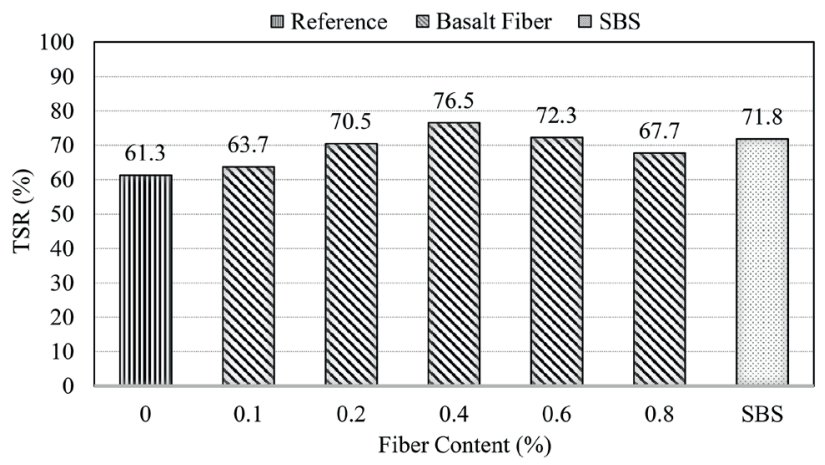

Fig. 11 Tensile strength ratio (TSR) for asphalt mixtures with various basalt fiber content
Table 6 Normalized experimental values due to reference ones

\begin{tabular}{|c|c|c|c|c|c|c|}
\hline & \multicolumn{5}{|c|}{ Content of basalt fiber $(\%)$} & \multirow{2}{*}{ SBS } \\
\hline & 0.1 & 0.2 & 0.4 & 0.6 & 0.8 & \\
\hline Resilient modulus & 1.06 & 1.17 & 1.85 & 3.40 & 2.45 & 3.25 \\
\hline Acc. strain at $3600 \mathrm{sec}$. & 0.65 & 0.55 & 0.48 & 0.72 & 0.81 & 0.65 \\
\hline $\begin{array}{l}\text { Perm. strain at } 2000 \\
\text { cycles }\end{array}$ & 0.96 & 1.08 & 0.99 & 1.02 & - & 0.42 \\
\hline $\begin{array}{l}\text { Indirect tensile } \\
\text { strength (uncond.) }\end{array}$ & 0.99 & 1.10 & 1.14 & 1.76 & 1.40 & 1.57 \\
\hline $\begin{array}{l}\text { Indirect tensile } \\
\text { strength (cond.) }\end{array}$ & 1.04 & 1.27 & 1.41 & 2.06 & 1.52 & 1.84 \\
\hline Tensile strength ratio & 1.04 & 1.15 & 1.25 & 1.18 & 1.10 & 1.17 \\
\hline
\end{tabular}

Note: Green color indicates the increasing, while red color shows decreasing.

The summary of comparative experimental results due to the reference specimens (no fiber additive) are given in Table 6. The best performance behavior were observed at $0.6 \%$ basalt fiber added specimens in terms of resilient modulus and indirect tensile strength values, while $0.4 \%$ fiber amount has the most effective accumulated strain in static creep test and tensile strength ratio. Moreover, SBS added ones have least permanent strain within dynamic creep test.

\section{Conclusions}

The following conclusions can be drawn from this study, which consists of the effect of basalt fiber addition to the alternative usage of conventional cellulosic fiber on design performance of SMA:

- When the additives in the SMA mixtures increase, the infiltration of bitumen decreases due to the draindown tests. The amount of fiber at around $0.6 \%$ and $0.8 \%$ made the draindown values stable. Basalt fiber provided 2.0-3.0 \% less stabilization value than the cellulosic fiber used in SBS-modified mixtures due to the viscosity of the polymer bitumen. However, the draindown values of all the percentages are above the standard limit of $0.3 \%$.

- It was determined that the resilient modulus increased by up to the $0.6 \%$ fiber content and thereafter the related parameter decreased. Furthermore, the addition of basalt fiber to the SMA mixtures seriously improved the rigidity and resistance against deformation of the SMA samples.

- While the amount of deformations decreased compared to the control samples at all the additive rates, the best results in terms of resistance against permanent deformation were obtained at the $0.4 \%$ addition case according to the results of the static creep test. 
- Since the temperature of the experiment is higher than the softening point, the bitumen reached the viscous region and the basalt fiber partially lost its positive effect in the matrix. Therefore, the permanent strain values of both the fiber added samples and the control sample were close to each other due to the dynamic creep test. On the other hand, the SBS added samples had much less deformation than the other specimens had, while the softening point value of the bitumen was not exceeded.

- The greatest indirect tensile strength results, including both the conditional and unconditional cases with respect to the moisture susceptibility test, were observed with values of around 1.6 $\mathrm{MPa}$ and 1.1 $\mathrm{MPa}$ for $0.6 \%$ basalt fiber content. In addition, the tensile strength ratio values were located above the limit value for $0.2 \%$ to $0.6 \%$ fiber addition, although the water-conditioning effect decreased the interaction resistance between the bitumen and aggregate.

\section{References}

[1] Behbahani, H., Nowbakht, S., Fazaeli, H., Rahmani, J. "Effects of Fiber Type and Content on the Rutting Performance of Stone Matrix Asphalt", Journal of Applied Sciences, 9(10), pp. 19801984, 2009.

\section{https://doi.org/10.3923/jas.2009.1980.1984}

[2] Blazejowski, K. "Stone Matrix Asphalt, Theory and Practice", 1st ed., CRC Press, Boca Raton, FL, USA, 2011.

[3] General Directorate of Highways of Turkey "Technical Specification of Highways (TSH)", Ministry of Transportation and Infrastructure, Ankara, Turkey, 2013. (in Turkish)

[4] Brown, E. R., Cooley, L. A. "Designing Stone Matrix Asphalt Mixtures for Rut-Resistant Pavements", National Cooperative Highway Research Program, Washington, DC, USA, Rep. NCHRP 425, 1999.

[5] Wu, S., Ye, Q., Li, N. "Investigation of rheological and fatigue properties of asphalt mixtures containing polyester fibers", Construction and Building Materials, 22(10), pp. 2111-2115, 2008.

https://doi.org/10.1016/j.conbuildmat.2007.07.018

[6] Maurer, D. A., Malasheskie, G. J. "Field performance of fabrics and fibers to retard reflective cracking", Geotextiles and Geomembranes, 8(3), pp. 239-267, 1989. https://doi.org/10.1016/0266-1144(89)90005-8

[7] Tóth, C., Soós, Z. "The effect of VIATOP® plus FEP on the stiffness and low temperature behaviour of hot mix asphalts", épitőanyag Journal of Silicate Based and Composite Materials, 67(4), pp. 126$131,2015$.

https://doi.org/10.14382/epitoanyag-jsbcm.2015.20

[8] Kandhal, P. S. "Designing and constructing SMA mixtures: Stateof-the-practice", National Asphalt Pavement Association, Lanham, MD, USA, Rep. 122, 2002.
- In general, the experimental results show that the addition of basalt fiber improves less in the case of exceeding the softening point and decreasing the viscosity at high temperatures. However, it improves the tensile strength and creep strength at normal and low temperatures, because of the creation of new bonds in the matrix.

- It is appropriate to select the optimum amount of basalt fiber at around $0.6 \%$ to prevent the draindown of bitumen as well as considering the results of the earlier mentioned performance tests. Therefore, basalt fiber can be confidently used as an alternative to cellulosic fiber in the design of SMA mixtures. On the other hand, the permanent deformation characteristics of different fiber lengths can also be investigated due to the more homogenous matrix and can be obtained by adding shorter fiber lengths.

[9] Liu, Z. H., Chen, C. Y., Qin, R. J., Zou, X. T. "Research to Performance of Basalt Fibre Strengthen SBS Modified Asphalt Mixture", Advanced Materials Research, 446-449, pp. 191-195, 2012. https://doi.org/10.4028/scientific5/amr.446-449.191

[10] Liu, K., Zhang, W. H., Wang, F. "Research on Cryogenic Properties of Different Fiber Asphalts and Mixtures", Advanced Materials Research, 146-147, pp. 238-242, 2011. https://doi.org/10.4028/www.scientific.net/amr.146-147.238

[11] Morova, N. "Investigation of usability of basalt fibers in hot mix asphalt concrete", Construction and Building Materials, 47, pp. 175-180, 2013. https://doi.org/10.1016/j.conbuildmat.2013.04.048

[12] Wang, D., Wang, L., Gu, X., Zhou, G. "Effect of Basalt Fiber on the Asphalt Binder and Mastic at Low Temperature", Journal of Materials in Civil Engineering, 25(3), pp. 355-364, 2013. https://doi.org/10.1061/(asce)mt.1943-5533.0000605

[13] Gu, X., Xu, T., Ni, F. "Rheological behavior of basalt fiber reinforced asphalt mastic", Journal of Wuhan University of TechnologyMaterials Science Edition, 29(5), pp. 950-955, 2014. https://doi.org/10.1007/s11595-014-1026-0

[14] Qin, X., Shen, A., Guo, Y., Li, Z., Lv, Z. "Characterization of asphalt mastics reinforced with basalt fibers", Construction and Building Materials, 159, pp. 508-516, 2018.

https://doi.org/10.1016/j.conbuildmat.2017.11.012

[15] ASTM "ASTM C131/C131M-14 Standard Test Method for Resistance to Degradation of Small-Size coarse Aggregate by Abrasion and Impact in the Los Angeles Machine", American Society for Testing Materials, West Conshohocken, PA, USA, 2014.

[16] ASTM"ASTM C88/C88M-18 Standard Test Method for Soundness of Aggregates by Use of Sodium Sulfate or Magnesium Sulfate", American Society for Testing Materials, West Conshohocken, PA, USA, 2018. 
[17] TSE "TS EN 933-3 Tests for geometrical properties of aggregates Part 3: Determination of particle shape - Flakiness index", Turkish Standards Institute, Ankara, Turkey, 2012.

[18] TSE "TS EN 1097-8 Tests for mechanical and physical properties of aggregates - Part 8: Determination of the polished stone value", Turkish Standards Institute, Ankara, Turkey, 2010.

[19] Tayebali, A., Kusam, A., Bacchi, C. "An Innovative Method for Interpretation of Asphalt Boil Test", Journal of Testing and Evaluation, 46(4), pp. 1622-163, 2018.

https://doi.org/10.1520/jte20160383

[20] ASTM "ASTM C127-15 Standard Test Method For Relative Density (Specific Gravity) And Absorption Of Coarse Aggregate", American Society for Testing Materials, West Conshohocken, PA, USA, 2015.

[21] ASTM "ASTM C128-15 Standard Test Method for Relative Density (Specific Gravity) and Absorption of Fine Aggregate", American Society for Testing Materials, West Conshohocken, PA, USA, 2015.

[22] TSE "TS EN 1097-7 Tests for mechanical and physical properties of aggregates - Part 7: Determination of the particle density of filler - Pyknometer method", Turkish Standards Institute, Ankara, Turkey, 2009.

[23] ASTM "ASTM D5/D5M-13 Standard Test Method for Penetration of Bituminous Materials", American Society for Testing Materials, West Conshohocken, PA, USA, 2013.

[24] ASTM "ASTM D36/D36M-14e1 Standard Test Method for Softening Point of Bitumen (Ring-and-Ball Apparatus)", American Society for Testing Materials, West Conshohocken, PA, USA, 2014.

[25] ASTM "ASTM D113-17 Standard Test Method for Ductility of Asphalt Materials", American Society for Testing Materials, West Conshohocken, PA, USA, 2018.

[26] ASTM "ASTM D92-18 Standard Test Method for Flash and Fire Points by Cleveland Open Cup Tester", American Society for Testing Materials, West Conshohocken, PA, USA, 2018.

[27] ASTM "ASTM D70-18 Standard Test Method for Density of SemiSolid Asphalt Binder (Pycnometer Method)", American Society for Testing Materials, West Conshohocken, PA, USA, 2018.

[28] ASTM "ASTM C1125-89 Standard Test Method for Penetration Index of Asbestos", American Society for Testing Materials, West Conshohocken, PA, USA, 2015.

[29] ASTM "ASTM D6/D6M-95 Standard Test Method for Loss on Heating of Oil and Asphaltic Compounds", American Society for Testing Materials, West Conshohocken, PA, USA, 2018.
[30] AASHTO "AASHTO T 166 Standard Method of Test for Bulk Specific Gravity (Gmb) of Compacted Hot Mix Asphalt (HMA) Using Saturated Surface-Dry Specimens", American Association of State Highway and Transportation Officials, Washington, DC, USA, 2016.

[31] AASHTO "AASHTO T 209 Standard Method of Test for Theoretical Maximum Specific Gravity (Gmm) and Density of Hot Mix Asphalt (HMA)", American Association of State Highway and Transportation Officials, Washington, DC, USA, 2012.

[32] Abtahi, S. M., Sheikhzadeh, M., Hejazi, S. M. "Fiber-reinforced asphalt-concrete - A review", Construction and Building Materials, 24(6), pp. 871-877, 2010.

https://doi.org/10.1016/j.conbuildmat.2009.11.009

[33] TSE "TS EN 12697-18 Bituminous mixtures - Test Methods Part 18: Binder Drainage", Turkish Standards Institute, Ankara, Turkey, 2018.

[34] TSE "TS EN 12697-26 Bituminous mixtures - Test Methods for Hot Mix Asphalt - Part 26: Stiffness", Turkish Standards Institute, Ankara, Turkey, 2012.

[35] Brown, E. R., Kandhal, P. S., Zhang, J. "Performance testing for hot mix asphalt", National Center for Asphalt Technology, Auburn, AL, USA, Rep. NCAT01-05, 2001.

[36] Witczak, M. W., Kaloush, K., Pellinen, T., El-Basyouny, M., Von Quintus, H. "Simple Performance Test for Superpave Mix Design", National Cooperative Highway Research Program, Washington, DC, USA, Rep. NCHRP 465, 2002.

[37] Zhou, F., Scullion, T., Sun, L. "Verification and Modeling of Three-Stage Permanent Deformation Behavior of Asphalt Mixes", Journal of Transportation Engineering, 130(4), pp. 486-494, 2004. https://doi.org/10.1061/(asce)0733-947x(2004)130:4(486)

[38] Ahmedzade, P., Yilmaz, M. "Effect of polyester resin additive on the properties of asphalt binders and mixtures", Construction and Building Materials, 22(4), pp. 481-486, 2008. https://doi.org/10.1016/j.conbuildmat.2006.11.015

[39] Shen, D.-H., Wu, C.-M, Du, J.-C. "Performance evaluation of porous asphalt with granulated synthetic lightweight aggregate", Construction and Building Materials, 22(5), pp. 902-910, 2008. https://doi.org/10.1016/j.conbuildmat.2006.12.008

[40] AASHTO "AASHTO T 283 Standard Method of Test for Resistance of Compacted Asphalt Mixtures to Moisture-Induced Damage", American Association of State Highway and Transportation Officials, Washington, DC, USA, 2014. 